\title{
Correction to: Low-moderate arsenic exposure and respiratory health in American Indian communities in the Strong Heart Study
}

Martha Powers ${ }^{1 *}$, Tiffany R. Sanchez ${ }^{2}$, Maria Grau-Perez ${ }^{1}$, Fawn Yeh ${ }^{3}$, Kevin A. Francesconi ${ }^{4}$, Walter Goessler ${ }^{4}$, Christine M. George ${ }^{5}$, Christopher Heaney ${ }^{1,6}$, Lyle G. Best ${ }^{7}$, Jason G. Umans ${ }^{8}$, Robert H. Brown ${ }^{1,9}$ and Ana Navas-Acien ${ }^{1,2,6}$

\section{Correction to: Environ Health}

https://doi.org/10.1186/s12940-019-0539-6

The original version of this article [1], published on 28 November 2019, contained incorrect title. In this Correction the affected part of the article is shown.

Incorrect title:

Low-moderate arsenic exposure and respiratory in American Indian communities in the Strong Heart St

Correct title:

Low-moderate arsenic exposure and respiratory health in American Indian communities in the Strong Heart Study

In this correction article the title is shown correct.

\section{Author details}

${ }^{1}$ Department of Environmental Health and Engineering, Johns Hopkins Bloomberg School of Public Health, 615 N. Wolfe St, Baltimore, MD, USA. ${ }^{2}$ Department of Environmental Health Sciences, Columbia University Mailman School of Public Health, New York, NY, USA. ${ }^{3}$ Center for American Indian Health Research, University of Oklahoma Health Sciences Center, College of Public Health, Oklahoma City, OK, USA. ${ }^{4}$ Institute of Chemistry Analytical Chemistry, Graz, Austria. ${ }^{5}$ Department of International Health, Johns Hopkins Bloomberg School of Public Health, Baltimore, MD, USA. ${ }^{6}$ Department of Epidemiology, Johns Hopkins Bloomberg School of Public Health, Baltimore, MD, USA. 7Missouri Breaks Industries Research, Inc, Eagle Butte, SD, USA. ${ }^{8}$ MedStar Health Research Institute, Hyattsville, MD, USA, Georgetown-Howard Universities Center for Clinical and Translational Science, Washington, DC, USA. ${ }^{9}$ Department of Anesthesiology and Critical Care Medicine, Johns Hopkins School of Medicine, Baltimore, MD, USA.
Published online: 26 February 2020

Reference

1. Powers, et al. Low-moderate arsenic exposure and respiratory health in American Indian communities in the Strong Heart Study. Environ Health. 2019;18:104. https://doi.org/10.1186/s12940-019-0539-6 .

The original article can be found online at https://doi.org/10.1186/s12940019-0539-6

* Correspondence: mpower24@jhu.edu

'Department of Environmental Health and Engineering, Johns Hopkins

Bloomberg School of Public Health, 615 N. Wolfe St, Baltimore, MD, USA

Full list of author information is available at the end of the article

(c) The Author(s). 2020 Open Access This article is distributed under the terms of the Creative Commons Attribution 4.0 International License (http://creativecommons.org/licenses/by/4.0/), which permits unrestricted use, distribution, and reproduction in any medium, provided you give appropriate credit to the original author(s) and the source, provide a link to the Creative Commons license, and indicate if changes were made. The Creative Commons Public Domain Dedication waiver (http://creativecommons.org/publicdomain/zero/1.0/) applies to the data made available in this article, unless otherwise stated. 